\title{
Crise orgânica, governos e seus impactos na América Latina
}

\section{Organic crisis, governments and their impacts in Latin America}

\author{
Cláudia Maria Costa Gomes* \\ Gonzalo Adrián Rojas**
}

\begin{abstract}
Resumo - Este ensaio tem como objetivo analisar os processos recentes no cenário politico da América Latina, a partir de um a partir da conjuntura de crise, com foco nas relações políticas e de alianças entre os governos pós-neoliberais e as frações de classe da burguesia, no contexto neoliberal e sob o modo de regulação governista, o qual apresenta uma configuração específica de estabilização de forças que entrecruzam o terreno da dominação e da direção do processo social, aparecendo na análise como o mote de definição histórica desse período, em um marco expressivo na aplicação de medidas de austeridade frente ao ajuste econômico, com perspectivas de agravamento que enfatiza as limitações das democracias latino-americanas para a turbulência do momento. A metodologia utilizada consiste em revisão de literatura com base em pesquisas sobre a temática.
\end{abstract}

Palavras-chave: Crise, América Latina, governos pós-neoliberais.

\begin{abstract}
This essay aims to analyze the recent processes in the political scenario of Latin America, starting from the crisis conjuncture, with a focus on political relations and alliances between post-neoliberal governments and class fractions of the bourgeoisie, in the neoliberal context and under the mode of government regulation, which presents a specific configuration of stabilization of forces that intersect the terrain of domination and the direction of the social process, appearing in the analysis as the mote of historical definition of that period, in an expressive framework in the implementation of austerity measures in the face of economic adjustment, with prospects of aggravation that emphasizes the limitations of Latin American democracies to the turbulence of the moment. The methodology used is a literature review based on research on the subject.
\end{abstract}

Keywords: Crisis, Latin America, post-neoliberal governments.

\footnotetext{
*Assistente Social. Doutora em Serviço Social pela UFPE e Professora Permanente do Programa de Pós-graduação em Serviço Social (PPGSS) da UFPB. Correspondência: Rua Luís Moreira Gomes, 389/apt.102, Residencial Garnet - Bancários - João Pessoa - PB. CEP: 58052-295. Email: <claudiac_gomes@hotmail.com>.

** Cientista político. Doutor em Ciência Política pela USP e Professor Permanente do Programa de Pós-graduação em Ciências Sociais (PPGCS) da UFCG. Correspondência: Rua Aprígio Veloso, 882/sl. 409, bloco BA-Hall das Placas - Bodocongó - Campina Grande - PB. CEP: 58.429-900. Email: <gonzalorojas1969@hotmail.com>.
} 


\section{Introdução}

O artigo tem como objetivo problematizar a partir da conjuntura de crise, os processos recentes no cenário politico da América Latina, a partir de um corte analítico que privilegia no limite, as relações políticas e de alianças entre os governos pós-neoliberais e as frações de classe da burguesia para garantir o consentimento ativo de um projeto de poder, o qual é objeto desta reflexão' .

Trata-se do significado e abrangência das recentes mudanças no subcontinente, recortada por circunstâncias políticas aonde o neoliberalismo assume dia após dia centralidade sob o modo de regulação governista, o qual apresenta uma configuração específica de estabilização de forças que entrecruzam o terreno da dominação e da direção do processo social, aparecendo na análise como o mote de definição histórica desse período, em um marco expressivo na aplicação de medidas de austeridade frente ao ajuste econômico, com perspectivas de agravamento que enfatiza as limitações das democracias latino-americanas para a turbulência do momento.

No centro da reflexão está suposto o argumento de que a caracterização do momento atual comporta elementos de um debate mais estrutural, do ponto de vista econômico o qual pressupõe uma analise sobre a crise e seus rebatimentos no âmbito da superestrutura, a partir de uma ideia-chave: a existência de um giro à direita na conjuntura da América Latina.

Nesta direção procuramos fazer uma análise sobre as alianças, os arranjos políticos e os interesses das frações de classe no poder, capturando o jogo de forças que influenciam a dinâmica governista latino-americana, com uma síntese notável para os limites de um artigo.

Salvaguardadas as polêmicas e diversas concepções entre a heteróclita tradição marxista, é possível dizer, em meio à vastidão de possibilidades e direcionamentos explicativos, que algumas questões nos parecem fundamentais para entender o momento analisado: partimos do pressuposto de que estamos assistindo a um fenômeno político mais geral na América Latina que poderíamos chamar de fim do ciclo de um conjunto heterogêneo de governos que se apresentavam com alguns elementos discursivos, em maior ou em menor medida, como críticos do neoliberalismo, sejam em versões autodenominadas "neodesenvolvimentistas", como no Brasil e na Argentina, ou "nacionalistas", como nos casos da Venezuela, Bolívia ou Equador. Essa é uma tendência geral, reconhecendo que cada um desses governos tem especificidades expressadas pela particular relação entre as

\footnotetext{
${ }^{1} \mathrm{O}$ ensaio integra os estudos e as pesquisas desenvolvidos no âmbito do GEPET - Grupo de Estudos e Pesquisas em Economia Política e Trabalho, vinculada ao Programa de Pós-Graduação em Serviço Social da Universidade Federal da Paraíba, em articulação com o PRÁXIS - Grupo de Estudos e Pesquisas sobre Estado e Luta de Classes na América Latina, vinculado ao Programa de Pós-graduação em Ciências Sociais (PPGCS) da Universisdade Federal de Campina Grande.
} 


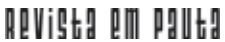

\} CRISE ORGÂNICA, GOVERNOS E SEUS IMPACTOS NA AMÉRICA LATINA - GOMES, C. M. C.; ROJAS, G. A. \}

DOI: $10.12957 /$ REP.2017.30374

alianças de classes e frações de classes no bloco no poder em suas respectivas formações econômico-sociais.

Essa caracterização nos levará a demonstrar que o avanço conservador e à direita no subcontinente, não expressam episódios isolados ou separados, mas uma unidade dialeticamente engendrada. Em razão disso, temos clareza que a tarefa de avaliar o período mais recente da América Latina, não é um desafio simples, sobretudo quando vemos que o legado das formas de reorganização da crise operadas pelas frações de classe das burguesias nacionais, pesa sobre o presente de uma forma bem mais substancial do que o fora em conjunturas anteriores. Particularmente porque agora, as disjuntivas dessa crise atualizam o caráter implacável do imperialismo e neocolonialismo, atestado pela conformação geopolítica mundial.

\section{As disjuntivas da América Latina nos marcos da crise orgânica}

América Latina se encontra num processo de "fim de ciclo" de um conjunto de governos que em sua heterogeneidade são denominados como "pós-neoliberais", "progressistas" o de "esquerda" e um giro a direita na superestrutura politica.

Nesse contexto e quando se aceleram todos os processos contraditórios da crise capitalista nos marcos do imperialismo contemporâneo e avanço da ofensiva burguesa sobre os trabalhadores, inexoravelmente abrese um campo de problematizações de ordem teórica e política como resposta à crise no interior dos projetos classistas, contribuindo para que se aprofundem os conflitos e a luta de classes na América latina na atual conjuntura.

Nossa hipótese, em relação à crise capitalista mundial de 2008 seguindo a interpretação de Gramsci é que estamos frente a uma crise orgânica, não só uma crise conjuntural, não só frente à crise de uma forma de capitalismo - à do modelo do capitalismo neoliberal - senão frente a uma crise geral do capitalismo (ROJAS, 2016).

Ensina Gramsci, que a crise embora constituinte do modo de produção e de troca - resultante da lei da queda da taxa de lucro - reflete profundamente a esfera política, uma vez que circunstâncias imediatas produzidas por situações econômicas expressam conjunturas políticas estratégicas. Daí que no centro de suas reflexões, economia e política estabelecem um vínculo profundo.

Para o pensador Sardo, a distinção entre crise orgânica e crise conjuntural é recorrente em sua análise, pois entende que a primeira é de maior amplitude e profundidade do que a segunda. Ou seja, a crise orgânica não está exclusivamente articulada à duração de uma crise conjuntural, é resultado de um conflito mais amplo entre a classe dominante e as demais frações de classe. Um tipo de crise que atinge as instituições, fazendo romper o bloco histórico vigente. 


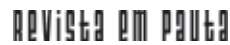

\} CRISE ORGÂNICA, GOVERNOS E SEUS IMPACTOS NA AMÉRICA LATINA - GOMES, C. M. C.; ROJAS, G. A. \} DOI: $10.12957 /$ REP.2017.30374

Estamos frente e uma crise profunda econômica, política e social que vai além das crises "normais" do capitalismo, as crises cíclicas, onde depois de um período de expansão temos um período de retração que que serve de impulso para um novo ciclo de expansão.

Na crise orgânica, a contradição dos vínculos causais entre estrutura e superestrutura, elevada a um patamar mais alto, provoca o conflito aberto entre frações de classes e grupos antagônicos, em virtude da incapacidade da burguesia dirigente dar conta dos problemas políticos, econômicos e culturais que eclodem na sociedade. Há o acirramento do conflito entre as classes fundamentais, abrindo-se, portanto, um período histórico repleto de convulsões sociais, políticas e econômicas (PORTELLI, 1977).

Pois bem, a configuração da crise aberta desde os anos setenta do século XX é determinante na formação de uma recomposição no interior do loco histórico a nível mundial, para responder as disjuntivas da acumulação capitalista nessa etapa de seu desenvolvimento histórico, centralizado pelo estagio imperialista contemporâneo, que tem no capital fictício sua forma de ser. Um bloco histórico onde a hegemonia é do capital financeiro sobre as demais frações do capital e as classes subalternas.

Por isso, se faz consequente analisar as determinações na estrutura vigente da composição orgânica do capital - com suas próprias leis dialéticas e tendenciais - os quais exige da burguesia dirigente e dos governos de plantão que os sustentam, uma serie de respostas e ajustes para garantir a recomposição das condições de valorização do capital e, por conseguinte, a desvalorização da forca de trabalho. Respostas, que significam no âmbito da movimentação burguesa a partir de seus projetos, impactos que incidem sobre os direitos do trabalho, no marco das conquistas democráticas. Em nossa avaliação essa análise, nada tem de economicista, senão que tem relação com a possibilidade realizar uma adequada análise estrutural na perspectiva de construção de uma melhor intervenção na luta de classes.

Dessa forma é possível dizer que a reorganização do desenvolvimento das forças produtivas, como medidas de enfrentamento da crise, gerou a necessidade de recomposição e ajuste entre as forças produtivas e os aparelhos de hegemonia, demandando uma nova forma de reestruturar a produção, precarizando e flexibilizando o mundo do trabalho e a sua divisão social e técnica, implementando mecanismos sócio-políticos que assegurassem à sua reprodução, a exemplo de uma maior abertura comercial e financeira, reforma nos mercados laborais, alterações na forma de apropriação/acumulação do capital sob as bases do rentismo e acréscimo da parte do valor produzido nas economias periféricas latino-americanas.

A rigor, a virulência da crise revela um processo de profunda transformação do capitalismo desde o desenvolvimento do padrão fordista/keynesiano, o qual se caracterizou pela modalidade de hegemonia do grande capital produtivo no bloco histórico ao constituir mecanismos de contra tendência à queda da taxa de lucro. 


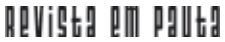

\} CRISE ORGÂNICA, GOVERNOS E SEUS IMPACTOS NA AMÉRICA LATINA - GOMES, C. M. C.; ROJAS, G. A. \}

DOI: $10.12957 /$ REP.2017.30374

Essa caracterização histórica comporta elementos de um debate mais estrutural do ponto de vista econômico, o qual pressupõe o conceito de crise que abrange uma variedade de significados que se pode encontrar em análises marxistas de diversas procedências e fundamentos e que nos limites de um artigo, não cabe explicitar.

Importa saber, como categoria analítica, que o conceito de crise se define nos marcos do processo de acumulação, revelando em um nível mais simples, as barreiras e os limites do capital entre a mercadoria e o dinheiro no âmbito da circulação, que se expressa no sentido mercantil, na incapacidade do capital de venda e compra de mercadorias, irrompendo, portanto, ao nível mais abstrato, a desproporcionalidade em seu processo de autovalorização. Explica Marx (2002, p. 285) "A desarmonia entre a produção imediata e a circulação, resulta a possibilidade de uma crise. Desde que as diferentes fases da circulação não se encadeiem de forma contínua, há crise".

Os leitores dessa tradição teórica sabem, que atravancado o movimento expansivo de acumulação, o capital empreende uma batalha mundial para restaurar a rentabilidade e impulsionar as taxas de lucro e o faz sob o "triunfo ideológico" do neoliberalismo, que reafirma de maneira imperativa, o significado das instâncias políticas e econômicas que consolidam a estruturação de uma crise orgânica sem precedentes, adverso inclusive da conformação anterior, a qual compunha o bloco hegemônico do grande capital no segundo pós-guerra.

Na América Latina, a prerrogativa da crise operada pelo neoliberalismo não se restringe excepcionalmente à dificuldade de escassez de produtos de matéria prima, elevação dos preços das commodities, redução das transferências de recursos no mercado de crédito internacional, ou ao problema do desemprego estrutural na região, mas ao efeito do esgotamento do padrão de financiamento público da economia capitalista, conduzidas por políticas de privatização/liquidação de empresas estatais e serviços públicos.

Isso equivale a dizer, que ao longo dos anos, à medida que o círculo do financiamento público, reprodução da força de trabalho e acumulação capitalista foi se aprofundando, a estabilidade desse modelo começa a oscilar, provocando um retraimento nos investimentos e na renda que deixam de ser cada vez mais nacionais, crescendo com isto, a internacionalização que retirou parte dos ganhos fiscais do Estado, deixando aos fundos públicos nacionais, o ofício de permanecer articulando e financiando a reprodução do capital e a força de trabalho. Tal processo tem sido acentuado pela manipulação dos diversos dispositivos de política econômica nos países dependentes, através das contrarreformas.

A concretização dessas medidas apresenta-se, particularmente, como um fenômeno arcaico de retomada da extração de mais valor na contemporaneidade e que se desenvolve como uma "reprodução não ex- 


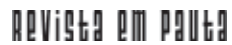

\} CRISE ORGÂNICA, GOVERNOS E SEUS IMPACTOS NA AMÉRICA LATINA - GOMES, C. M. C.; ROJAS, G. A. \} DOI: $10.12957 /$ REP.2017.30374

pandida" ou ampliada, tal como tratada por Marx. Contraditoriamente, é marcada pela especulação monetária rentável, de que é exemplo o "capital portador de juros", convertido na forma social dominante no plano das economias internacionais e a tendência decrescente do valor de uso, cujas consequências se expressam por meio da precarização da força de trabalho e aniquilamento dos recursos naturais, cada vez mais escassos (GOMES, 2016).

Assim, por meio de um amplo consenso social, aonde a esfera financeira torna-se determinante para as novas regras em escala mundial, o Estado desempenha cada vez mais o papel de executor dos interesses da burguesia dirigente, atuando no abastecimento da liquidez necessária (monetarização do capital fictício por meio de títulos da dívida) para estabilizar os mercados financeiros. E o faz garantindo a ampliação dos recursos públicos no resgate de instituições financeiras com problemas de solvência/ liquidez, criando títulos públicos adicionais para a venda nos mercados (CARCANHOLO, 2017).

Desta forma, as céleres mudanças do capital financeiro produziram uma verdadeira epopeia de articulação de interesses sob a forma de lobbying e especulação sem precedentes, em que negócios nas áreas de câmbio, ações, bônus, títulos das dívidas públicas e derivados em geral se desenvolveram numa rapidez muito maior que as atividades produtivas e comerciais. A produção de valor gerado nessa área tem desacelerado o investimento de empresas produtivas, que na impossibilidade de gerar lucros nas mesmas proporções que a área financeira, se vê obrigados a realocar parte de seus recursos para o setor financeiro, comprometendo a sua atividade primária.

Definitivamente, esse cenário traduz mutações no interior do estágio imperialista, conformando uma etapa na formação de uma nova articulação entre as frações de classes no interior do bloco histórico; nela a realidade se torna mais complexa, em função da fase de expansão e concentração do capital sob o marco da internacionalização da divisão social do trabalho.

Em América Latina depois de um crescimento econômico baseado fundamentalmente na exportação de matérias primas, diante de uma extensa reprimarização das economias latino-americanas, com alta nos preços das commodities, os quais em grande medida financiaram tal expansão, gerou um crescimento inédito em um contexto de crise. Contudo, a queda do preço das matérias primas no mercado mundial capitalista é uma realidade que os governos latino-americanos não têm controle e o fato de nenhum deles questionar a divisão internacional do trabalho, imposta pelo imperialismo - é inexorável. Como a crise econômica tem relação com as crises políticas, impacta com força e acaba com os discursos por meio do qual se ocultava a reprimarização real das economias (ROJAS, 2016).

Assim, para os países latino-americanos, a cristalização desse quadro deletério se deu a partir da definição de um processo estrutural de reprodução da dependência e da crise, o que corresponde ao maior endividamento 


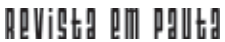

\} CRISE ORGÂNICA, GOVERNOS E SEUS IMPACTOS NA AMÉRICA LATINA - GOMES, C. M. C.; ROJAS, G. A. \}

DOI: $10.12957 /$ REP.2017.30374

dos Estados, em função das medidas aplicadas pelos países centrais, de medidas voltadas para o enfrentamento da queda da taxa geral de lucro, levando os fluxos de capitais a migrar do centro para a periferia latino-americana, tanto quanto os capitais de empréstimos, como os capitais voláteis especulativos, com redução das reservas internacionais, desaceleração dos volumes de exportação, desvalorização das taxas de câmbio e pressões inflacionárias, criando assim, uma forte instabilidade econômica, politica e social e maior ajuste das reformas neoliberais no subcontinente.

Diríamos então, que as necessidades vitais do capital se renovam e as formas históricas possíveis de garantir a acumulação assumem características diversas, redefinindo a composição do polo hegemônico da burguesia nos países centrais.

Do ponto de vista estratégico, a quebra das barreiras econômicas, por via de mecanismos políticos, consiste, necessariamente, na maior liberdade para o capitalismo fixar as novas regras aos países periféricos, com destaque ao papel do Banco Mundial e do Fundo Monetário Internacional, instituições financeiras reorientadas após o declínio do Bretton Wood, o qual impôs inúmeras reformas e ajustes estruturais, ocasionando saldos positivos para o capital. Segundo François Chesnais,

[...] como estratégia de superar as lacunas herdadas da crise de 1929, o sistema monetário internacional Bretton Woods proporcionou o crescimento econômico do pós-guerra vinte e três anos depois da dissolução desse sistema, por decisão unilateral dos EUA em 1971 (1996, p. 248).

Portanto, a súmula política desses ajustes na América Latina implicou na padronização do receituário neoliberal que se seguiu nas últimas décadas, com cortes nas despesas com políticas sociais e investimentos, reforma da previdência, flexibilização do mercado financeiro para a presença de bancos internacionais, programa de privatizações, desregulamentação das relações trabalhistas (contrarreformas), entre outros. Trata-se de políticas que incidem em uma radical desvalorização da força de trabalho, deteriorando as condições de vida da maioria da população.

Isso revela o movimento contraditório que demarca esta quadra histórica, que numa leitura acrítica, tende a esconder a sua funcionalidade à ordem do capital, demonstrando mais do que nunca, sua capacidade transformista para efetivar a dominação, realizada mutatis mutantis num processo contínuo de passivização da ordem, onde o Estado se redireciona para organizar o consenso e articular as práticas classistas.

A orientação da política económica não se dilui no terreno teórico. Decanta-se no terreno político, em que se confrontam interesses. Em primeiro lugar, na luta de classes, onde se enfrenta os interesses dos capitalistas e trabalhadores, em segundo lugar a pugna competitiva que enfrenta as distintas frações do capital e os distintos capitais individuais entre si (ARRIZABALO, 2016, p. 373, tradução nossa). 


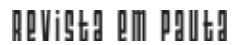

\} CRISE ORGÂNICA, GOVERNOS E SEUS IMPACTOS NA AMÉRICA LATINA - GOMES, C. M. C.; ROJAS, G. A. \} DOI: $10.12957 /$ REP.2017.30374

Isso reflete ao nível mais abstrato, aspectos ideológicos na conformação, produção e organização do consenso, sob o qual a hegemonia se realiza e dos quais disputam grupos antagonicamente opostos. Em diversas interpretações sobre as disputas hegemônicas que conformam certos desequilíbrios em determinados padrões de dominação no interior dos Estados latino-americanos para a formação do consenso, intriga a determinados analistas de plantão, a tendência a um maior extremismo liberal dos regimes, para a manutenção de um padrão de supremacia estabelecidos pelas burguesas nos seus respectivos Estados.

Para nós, que refletimos a América Latina, desde a perspectiva do colonialismo, semicolonialíssimo, imperialismo e outras formas de relações hierárquicas de domínio nestas nações; a formação de um projeto de poder que acaudilha a política do Estado nos países do subcontinente, desde sempre esteve às voltas com uma questão crucial: a relação subordinada que eles estabelecem com os países capitalistas centrais.

Do predomínio semicolonial à dominação imperialista, os predicados de dependência na economia, na sociedade, na política e na cultura dos países latino-americanos conferem a seus processos de desenvolvimento, uma forte marca de heteronomia, herdeiras da formação sócio histórica do subcontinente.

Portanto, no momento atual, o que está em jogo é o rearranjo dos mecanismos político-institucionais a uma adequação homóloga e terminante às novas condições de acumulação do capital. Isso significa dizer, que a crise atual é apenas uma manifestação particular radicada em uma crise orgânica do capitalismo, que se apresenta, sobretudo, como uma crise de hegemonia, revelando assim, a incapacidade da burguesia dirigente em administrar as exigências da acumulação mundial do capital e os próprios fundamentos de adesão e consentimento do status quo. Mas logicamente que não são movimentos só da estrutura, senão que tem relação com as classes e as frações de classes na sua luta inter-burguesa e fundamentalmente com a luta de classes nos confrontos com a classe trabalhadora e setores subordinados da sociedade.

Nesse sentido, observamos que a conjuntura atual latino-americana é marcada pela crise orgânica, os quais deve-se analisar país por país. No caso do Brasil, foram visíveis no último decênio, diversas situações com elementos de direita com a expansão dos aparelhos coercitivos (forças armadas, polícia e judiciário) e por uma etapa de criminalização da pobreza, de militarização das expressões da questão social, com o monitoramento grevista, das leis e da própria intervenção do Estado na economia que se ampliaram, sobretudo em variáveis públicos dos juros, do orçamento e câmbio. Demonstrando com isso a capacidade que o Estado, junto com o grande capital nacional e internacional tem de expropriar a classe trabaIhadora e explorá-la na extração de mais valia nas suas formas absoluta e relativa. 


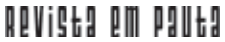

\} CRISE ORGÂNICA, GOVERNOS E SEUS IMPACTOS NA AMÉRICA LATINA - GOMES, C. M. C.; ROJAS, G. A. \}

DOI: $10.12957 /$ REP.2017.30374

Isso explica muito a expansão dos aparelhos coercitivos tradicionais e o papel do judiciário nos processos da operação lava-jato no Brasil, como aperfeiçoamento e ampliação de tais aparelhos para a exploração e expropriação do Estado e seus diversos aparelhos de geração de consenso, dos quais é exemplar o discurso ideológico com elementos conservadores e um discurso fascistizante, com implicações diretas em sua condição democrática.

Nestas situações, de forma um pouco mais ou menos organizada entre os países latino-americanos, as saídas políticas, mesmo entre aqueles que aspiram à continuidade destes governos, se dão por direita (ROJAS, 2016). Por exemplo, podemos mencionar o caso da Argentina, com o sucessor de Cristina Kirchner, o eleito a então Presidente desde 2015, Marcelo Macri, o qual aprofundou o modelo neoliberal. E no Brasil o golpe institucional desferido pelo PMDB contra o lulo-pestismo, os quais evidenciam a situação de fragilidade das formações políticas dos governos progressistas latino-americanos e as instabilidades de suas coalisões. É assim, muito esclarecedora a reflexão de Gramsci, sobre as variadas formas que podem assumir os partidos orgânicos no processo histórico:

Será necessária a ação política (em sentido estrito) para que se possa falar de "partido político"? Pode-se observar que no mundo moderno, em muitos países, os partidos orgânicos e fundamentais, por necessidade de luta ou por alguma outra razão, dividiram-se em frações, cada uma das quais assume o nome de partido e, inclusive, de partido independente. Por isso, muitas vezes o Estado-Maior intelectual do partido orgânico não per-tence a nenhuma dessas frações, mas opera como se fosse uma força dirigente em si mesma, superior aos partidos e às vezes reconhecida como tal pelo público (2000, p. 349-350).

Dialeticamente, podemos dizer que, si por um lado tem-se elementos à direita nas conjunturas políticas, que diferenciamos hoje de uma situação reacionária, por outro, tem-se fenômenos à esquerda. No caso do Brasil, a greve do dia 28 de abril de $2017^{2}$ colocou em cena a classe trabalhadora com seus métodos de luta, o que não se pode dizer o mesmo do dia 30 de junho, que só não foi maior em função da tática defensiva das centrais sindicais. No caso da Argentina, é exemplar o caso dos trabalhadores de Pepsico $^{3}$ que articula sindicalismo de base articulado com os Parlamentários Revolucionários do Partido de Trabalhadores Socialistas (PTS) conseguiram frear, por enquanto, à reforma trabalhista no país.

2 Cf. A greve geral mostrou a força de milhões de trabalhadores: nós podemos derrotar Temer. Disponível em: http://www.esquerdadiario.com.br/ A-greve-geral-mostrou-a-força-de-milhões-de-trabalhadores-nós-podemos-der rotar-Temer. Acesso em: 27 de agosto de 2017.

${ }^{3}$ Cf. PepsiCo: lucros milionários e demissões em massa na Argentina. Disponível em: http://www.esquerda diario.com.br/PepsiCo-lucros-milionários-e-demissões-em-massa-na-Argentina. Acesso em 28 de agosto de 2017. 


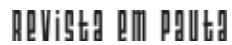

\} CRISE ORGÂNICA, GOVERNOS E SEUS IMPACTOS NA AMÉRICA LATINA - GOMES, C. M. C.; ROJAS, G. A. \} DOI: $10.12957 /$ REP.2017.30374

O que se observa claramente, ao longo da década é que o capital político destes governos progressistas foi desfazendo-se. Como "tudo que era sólido se desmancha no ar" (MARX, 1998), o modelo extrativista, centrado na mineração e expansão da matriz petroleira, foi bloqueado, o crescimento econômico desacelerou, a corrupção veio à tona e, eventualmente, o personalismo de alguns líderes marcou uma mudança no sentido do populismo.

Enquanto os impactos da crise se manifestam de forma diferenciada em termos geográficos e temporais, é inegável que nos últimos quatro anos, a crise impactou com força na América Latina e no Brasil. Estes movimentos na estrutura abalaram as bases sociais da mencionada reprodução política (ROJAS, 2016).

\section{Giro à direita na superestrutura da América Latina}

As classes dominantes do subcontinente sempre se mostraram incapazes de implementar sequer um projeto burguês nacional autônomo. Os integrantes dessa classe estão impetuosamente interessados em manter-se em um estado de atraso, se projetando para fora das suas próprias economias à procura de mercados externos aos quais possa se subordinar.

Em definitivo, pode-se dizer, que do predomínio colonial aos países semicoloniais à dominação imperialista, os predicados de dependência na economia, na sociedade, na política e na cultura dos países latino-americanos conferem a seus processos de desenvolvimento, uma forte marca de heteronomia e "modernização conservadora", herdeiras da formação sócio histórica do subcontinente.

Como assinalamos a configuração da crise aberta a partir de 2008, efetivamente consolida a formação de um novo bloco histórico a nível mundial que vinha se constituindo desde o ajuste neoliberal no final dos anos 1970, provocando assim uma rápida movimentação geopolítica para responder as disjuntivas da acumulação capitalista nessa etapa de seu desenvolvimento histórico, centralizado pelo estagio imperialista contemporâneo, cujos efeitos demolidores são múltiplos e conflituosos, não só do ponto de vista econômico e político, mas ao nível societário e civilizatório.

Poder-se-ia dizer, precisamente ao nível da conjuntura, na qual se mesclam políticas clássicas de ajuste, de transferência direta de ingressos aos setores mais concentrados, o avanço de um conservadorismo social e territorial através de uma "nova direita", que cada vez mais pressiona os governos de plantão para a adoção de medidas duras como resposta à crise,

Por conseguinte, a América latina, não passaria incólume, nem mesmo ao fato de mais de uma década de governos progressistas e integração latino-americana, indicando por assim dizer, que na conjuntura atual um "espectro ronda" o subcontinente: o espectro da direita. Senão vejamos: 


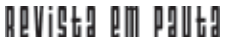

\} CRISE ORGÂNICA, GOVERNOS E SEUS IMPACTOS NA AMÉRICA LATINA - GOMES, C. M. C.; ROJAS, G. A. \} DOI: $10.12957 /$ REP.2017.30374

Em pouco menos de dois anos do escrito deste ensaio teórico, os governos de direita tem avançado: por meio da conquista das eletivas na Argentina com o triunfo de Mauricio Macri nas eleições presidenciais, a derrota de Evo Morales no referendo na Bolívia para sua re-reeleição, a destituição Dilma Rousseff da Presidência do Brasil através de um golpe institucional, a derrota de Maduro nas eleições legislativas na Venezuela. Tudo isso no marco de um avanço das medidas bonapartistas dos governos e particularidades em cada um desses países, os quais não cabem no limite de um artigo problematizar.

Ainda que se considere a heterogeneidade estrutural da América latina, podemos dizer que a conjuntura aponta processos de uma crise de regime em alguns países, acompanhando uma tendência que se internacionaliza, a exemplo da Colômbia, do Chile e do Brasil.

$\mathrm{Na}$ analise da realidade e para além da aparência, a pergunta seria? Podem-se conciliar políticas de ajuste e ao mesmo tempo respeitar os mandatos populares enquanto se caem os preços de petróleo e do conjunto das matérias primas no mercado internacional?

Como assinalamos, a economia condiciona claramente para explicar essa conjuntura de crise, mas abre as possibilidades de luta de classes. E assume um papel central desde um ponto de vista político para os governos de centro-esquerda, que lograram um êxito relativo e imediato em seus projetos populares, quando confrontados com o projeto neoliberal na América Latina.

Nos argumentos da bibliografia geral, afirma-se que nos discursos desses governos existe uma mudança na retórica frente ao modelo neoliberal, o que é um elemento ideológico e político significativo, mas não substantivo. No Brasil, isto está expresso na formulação da necessidade de erradicar a fome, no apelo aos pobres, inclusive na crítica as privatizações; [...] (ROJAS, 2014).

Nesse sentido, por um lado é bem verdade, que não se pode falar de um processo de direitização, sem apontar para a direção de um projeto revestido de autoritarismo de determinadas frações de classe, que agora se juntam ao bloco de poder neoliberal para travar uma batalha frente aos projetos denominados democráticos populares no subcontinente. A derrota dos governos pós-neoliberais expressam também a derrota dos governos democrático-populares, visíveis no caso brasileiro a partir das eleições de 2014. Na avaliação de Marcelo Badaró Mattos,

A manifestação mais acentuada dos efeitos da crise econômica
internacional sobre o país gerou uma resposta pós-eleitoral conservadora
e ortodoxa do governo reeleito, com a adoção das internacionalmente
conhecidas medidas de "austeridade". Os cortes do orçamento público
nas áreas sociais - especialmente na Educação - e a retirada de direitos
relativos ao seguro-desemprego e pensões de viúvas foram às primeiras
indicações de que mais uma vez a conta da crise deveria se paga pelos 
trabalhadores [...] assim, não haveria por que esperar que a classe trabalhadora fosse às ruas defender ${ }^{2}$ seu governo contra as ameaças da direita golpista (2016, p. 98).

Em uma análise classista coerente, é impossível não constatar o esgotamento do projeto conhecido historicamente no Brasil, como democrático popular, de base operária e hegemonizada pelas frações burguesas vinculadas ao capital financeiro nacional e internacional e às grandes burguesias internas brasileiras, que não coloca em questão a divisão internacional do trabalho construída pelo imperialismo e que se nega a assumir sua situação de semicolônia, o que permitiria sob a direção da classe trabalhadora empreender uma luta anti-imperialista e socialista consequente (ROJAS, 2014).

Por outro lado e em certa medida, a conjuntura política revela que há uma crise política, que não se resume apenas às disputas entre a direita conservadora e a esquerda supostamente possível no subcontinente, os quais se expressam no fracasso das polaridades entre projetos "democráticos" na América latina, que em termos estruturais mudaram muito pouco a estrutura de cada país com suas oposições à direita. Não estamos falando que tudo é o mais do mesmo, senão que é preciso entender que uma saída política pela esquerda tem que se basear na independência política dos dois blocos.

Pois bem, seguindo essa linha de argumentação, que parece indicar a necessidade de articulação desses elementos com o avanço da direita conservadora, que aprofundam sua aliança com o projeto neoliberal numa polarização com os projetos democráticos populares latino-americanos, os quais, em alguma medida permitiram tal avanço e agora só tem para oferecer um passado que não volta, pode-se dizer que a tentativa de uma democratização sem ruptura do Estado no marco de um programa democrático popular, se esgotou nos limites estruturais das possibilidades de ação política nos marcos do Estado burguês e da governabilidade (ROJAS, 2014b).

O avanço que se processa nessa reflexão é inequívoco, sobretudo quando se faz menção a vaga histórica deixada pelos projetos populares na América Latina, sob a qual a direita articula claramente para seu êxito, a mídia, o poder judiciário e o parlamento, cujas ideologias se apresentam como vontade geral, fazendo assim, ganhar-se tempo na superestrutura, enquanto agigantam-se a tensão social. Até porque é no terreno da moral e da cultura que a direita ganha espaço, tanto entre a classe média quanto em meio às classes subalternas. Na avaliação de Bianchi,

[...] o darwinismo social, uma ideologia que muitos consideravam confinada ao século XIX, ressurgiu com força, lado a lado com a defesa estridente da meritocracia. Junto com esses valores e essa ideologia espraiam-se desavergonhadamente, os discursos homofóbicos, machistas, racistas, autoritários e elitistas, as manifestações mais abjetas de uma 


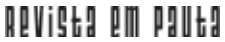

\} CRISE ORGÂNICA, GOVERNOS E SEUS IMPACTOS NA AMÉRICA LATINA - GOMES, C. M. C.; ROJAS, G. A. \}

DOI: $10.12957 /$ REP.2017.30374

visão de mundo hierárquica e preconceituosa que expressa às profundas clivagens sociais existentes em nossa sociedade (2016, p. 122).

Ao fim e ao cabo, esse cenário traduz mutações no interior do estágio imperialista. Configura um novo momento na conformação do novo bloco histórico; nela a realidade se torna mais complexa, porque a fase de expansão e concentração do capital, levado às ultimas consequências pela internacionalização da divisão social do trabalho, alterou o padrão de acumulação, condicionando a movimentação burguesa por meio de suas frações de classe, a redefinir suas estratégias em escala planetária, reabrindo um período histórico de regressão social em todos os quadrantes (ARRIZABALO, 2016).

Mais importante, todavia, é compreender que as disjuntivas da crise na América Latina, abre um espaço político-histórico para a luta de classes, o qual promete uma movimentação e aceleração nos processos sociais antagônicos, pondo fim a uma era de conciliação pelo alto e administração da ${ }^{2}$ pequena política ${ }^{2}$ de alianças, conduzidas pelos governos progressistas e democrático-populares.

Neste contexto mais que nunca é preciso recuperar de forma ofensiva o marxismo em termos teóricos e políticos para realizar uma análise das crises e das estruturas para organizados politicamente poder realizar uma melhor intervenção na luta de classes de forma independente dos patrões, dos governos e do Estado. Para não nos resignarmos a uma direita cada vez mais autoritária nem a miséria do possível que já vemos onde termina.

\section{Considerações finais}

Com a lucidez da complexidade dos aspectos que envolvem o tema e também a noção das limitações analíticas contidas neste artigo, arriscamos indicar que a conjuntura de crise na América Latina a partir de 2008, tem sido marcada pela dialética entre continuidades e rupturas nos marcos da quadra histórica neoliberal. Inserido num pacto essencialmente conservador, a hegemonia imperialista no subcontinente, reatualizou à ordem do dia, as raízes ideológicas da direita conservadora.

Como vimos essa caracterização do momento comporta elementos de um debate mais fundante do ponto de vista da crítica da economia política, o que significa analisar estrutura e conjuntura, sob as quais emerge e se desenvolve a crise capitalista na particularidade da América Latina, assinalando particularidades do percurso dos governos pós-neoliberais, que permitam desentranhar as contradições da vida política no subcontinente.

A rigor, pudemos verificar que o conjunto dessas mudanças, como referência ao pragmatismo político e econômico que se instalou nos países 


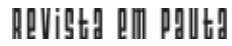

\} CRISE ORGÂNICA, GOVERNOS E SEUS IMPACTOS NA AMÉRICA LATINA - GOMES, C. M. C.; ROJAS, G. A. \}

DOI: $10.12957 /$ REP.2017.30374

latino-americanos, faz parte constitutiva da hegemonia neoliberal, correspondendo a uma estratégia de passivização do Estado, numa direção clara de construção de contra tendências e busca de espaço para a valorização do capital, que procura reverter à crise, sob a lógica da regressão social e do que se tem de mais atrasado e conservador em termos de projetos políticos.

Esse processo como já salientamos, se articula com tendências sociais mais amplas. $\mathrm{O}$ giro à direita na América Latina aparece como um momento de articulação política das forças e frações de classe burguesa, jogando um papel ofensivo na adequação tática aos problemas colocados pela ideologia da governabilidade em uma situação de crise orgânica, proporcionando continuidade ao quadro neoliberal.

Aos que apostaram que a realização das transformações necessárias à nossa sociedade, poderiam se dar sem rupturas profundas com os projetos políticos que compõem a base de sustentação do capital, acabaram por reforçar a racionalidade que alhures negavam, realizando o chamado transformismo. 
\} CRISE ORGÂNICA, GOVERNOS E SEUS IMPACTOS NA AMÉRICA LATINA - GOMES, C. M. C.; ROJAS, G. A. \} DOI: $10.12957 /$ REP.2017.30374

\section{Referências}

ARIZABALO, X. M. Capitalismo y Economía Mundial: Bases teóricas y análisis empírico para la compreensíon de los problemas económicos del siglo XXI. 2. Edición, Madrid: Instituto Marxista de Economía (IME), 2016. 720p.

BIANCHI, A. A guerra que estamos perdendo. In: Felipe Demier e Rejane Hoeveler (orgs.). A onda Conservadora: Ensaios sobre os atuais tempos sombrios no Brasil. Rio de Janeiro: Mauad X, 2016.

CARACANHOLO, M. D. Dependencia, Super-explotación del trabajo y Crisis: una interpretación desde Marx. Madrid: Maia ediciones, 2017.

CHESNAIS. F. (org). A mundialização financeira: gênese, custos e riscos. São Paulo: Xamã, 1998.

GOMES, C. M. C. La pobreza y la desigualdad integradas en el modelo de desarollo brasileño. Anais, III Conferencia Internacional de Sociología de las Políticas Públicas y Sociales: Globalización, Desigualdad y Nuevas Insurgencias. Facultad de Economía y Empresa. Universidad Zaragoza, 1-2 jun.2017.

. Em Busca do Consenso: Radicalidade democrática e afirmação de Direitos. 2. Ed. Rio de Janeiro: Lumen Juris, 2016.

. O neodesenvolvimentismo brasileiro e o programa de reformas de combate à pobreza na era Lula. Projeto de Pesquisa. CNPq/MCT/UNIVERSAL 14/2014. UFPB/João Pessoa.

MARX, K. O Capital: Crítica da economia política. Livro I, vol. 1, 20.ed Trad. Reginaldo Sant'Anna. Rio de Janeiro: Civilização Brasileira, 2002.

MARX, K.; ENGELS, F. O Manifesto Comunista. 7 edição (Tradução Maria Lúcia Como). Rio de Janeiro: Paz e Terra, 1998.

MATTOS, M. B. De Junho de 2013 a junho de 2015: elementos para uma análise da (crítica) conjuntura brasileira. In: DEMIER, F.; HOEVELER, R. (orgs.). A onda Conservadora: Ensaios sobre os atuais tempos sombrios no Brasil. Rio de Janeiro: Mauad X, 2016.

ROJAS, G. A. Fim do ciclo petista, as esquerdas no processo eleitoral e sua construção política. In: Dossiê esquerdas, eleições e transformações estruturais da sociedade brasileira. Setembro de 2014a. Disponível em: marxismo21.org/wp-content/uploads/2014/09/Gonzalo-Rojas-dossie.pdf Acesso: 20/05/2016.

A crítica da razão populista: bonapartismo e democracia nos governos "pós-neoliberais" latino-americanos? IX Encontro da ABCP. Brasília - DF, 04 a 07 de agosto de 2014b. Disponível em http://www.encontroabcp2014. cienciapolitica.org.br/resources/anais/14/1403749023_ARQUIVO_ rojasufcgabcp2014.pdf Acesso em: 26/06/2016. 


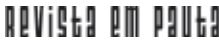

\{ CRISE ORGÂNICA, GOVERNOS E SEUS IMPACTOS NA AMÉRICA LATINA - GOMES, C. M. C.; ROJAS, G. A. \} DOI: $10.12957 /$ REP. 2017.30374

Recebido em 20 de agosto de 2017.

Aprovado para publicação em 05 de setembro de 2017. DOI: $10.12957 /$ rep.2017.30374

\section{(c) (i)}

A Revista Em Pauta: Teoria Social e Realidade Contemporânea está licenciada com uma Licença Creative Commons Atribuição 4.0 Internacional.

EM PAUTA, Rio de Janeiro - $1^{\circ}$ Semestre de 2017 - n. 39, v. 15, p. 17 - 32 